\title{
Low-Loss Microwave Dielectrics for Different Frequency Ranges
}

\author{
A. Belous* And O. Ovchar \\ V.I. Vernadskii Institute of General and Inorganic Chemistry NAS of Ukraine \\ 32/24 Palladin ave., 03680 Kyiv-142, Ukraine
}

\begin{abstract}
Depending on the operating frequency range of modern communication systems various microwave elements are required for effective operation of radio equipment. In this work potential ways of developing the microwave dielectric materials for different frequency ranges are discussed. It has been shown that temperature stable dielectrics with the permittivity of about 100, which are intended for the utilization in the decimetre wavelength band, can be developed by means of alio- and isovalent substitution in the cation sublattices of barium lanthanide titanates (BLTss) $\mathrm{Ba}_{6-x} \mathrm{Ln}_{8+2 x / 3} \mathrm{Ti}_{18} \mathrm{O}_{54}(\mathrm{Ln}=\mathrm{La}-\mathrm{Gd})$. The temperature behaviour of the permittivity and dielectric loss in the BLTss has been discussed in terms of both harmonic and anharmonic contributions to the phonons of the BLT crystal lattice. It has been shown that a slight deviation from the compositional stoichiometry in both A-site and B-site deficient perovskites $\mathrm{Ba}\left(\mathrm{M}_{1 / 3}^{2+} \mathrm{Nb}_{2 / 3}\right) \mathrm{O}_{3}(\mathrm{M}=\mathrm{Co}, \mathrm{Zn}, \mathrm{Mg})$ allows a prominent enhancement of their microwave quality factor $(Q)$. As a consequence, new dielectrics with the extremely high quality factor $(Q x f=90000-150000 \mathrm{GHz})$, which are intended for the utilization in the centimetre wavelength band, can be developed. Some examples of the possible implementation of the developed materials are also discussed.
\end{abstract}

PACS numbers: 61.05.cp, 61.72.Ff, 63.20.Ry, 77.22.Gm, 82.33.Pt, 84.40.Dc

\section{Introduction}

The development of modern radio communication systems operating in the microwave (MW) frequency range results in a sustainable demand for new dielectric materials combining high dielectric permittivity $(\varepsilon \gg 1)$, low dielectric loss $\left(\operatorname{tg} \delta<10^{-3}\right)$ or high quality factor $(Q=1 / \operatorname{tg} \delta)$ generally represented by the product $Q x f$, and near-zero temperature coefficient of resonant frequency $\left(\tau_{\mathfrak{f}}\right)$, which relates to the temperature coefficient of permittivity as $\tau_{\mathrm{f}}=-\tau_{\varepsilon} / 2-\alpha$ (where $\alpha$ is a linear thermal expansion coefficient). MW dielectrics are urgently required to reduce the size and the weight of radio equipment, as well as to provide low phase noises and high selectivity of MW devices.

The choice of the required permittivity of microwave materials is related to the operating frequency of radio components, excited oscillation modes, and the requirements to the optimum geometric dimensions. The $\varepsilon$ value determines the overall dimensions of the radio components. The effect of microminiaturization is based on the fact that the electromagnetic wavelength in dielectric media shortens by a factor of $\varepsilon^{1 / 2}$. Therefore, in the decimetre-wave band, high- $Q$ temperature stable materials with $\varepsilon \approx 100$ are needed, whereas in the centimetre and millimetre wavelength bands - when further minia-

* corresponding author; e-mail: belous@ionc.kar.net turization is no longer required - the materials with $\varepsilon \approx 10-40$ are generally used, for which the magnitude of the $Q$-factor becomes a crucial factor.

In this paper two types of dielectric materials intended for different frequency ranges are discussed together with a brief overview of some shortcomings in their processing and properties, as well as some solutions how to overcome the available problems.

\section{Results and discussion}

$$
\begin{aligned}
& \text { 2.1. } \mathrm{Ba}_{6-x} \mathrm{Ln}_{8+2 x / 3} \mathrm{Ti}_{18} \mathrm{O}_{54}(\mathrm{Ln}=\mathrm{La}-\mathrm{Gd}) \text { solid } \\
& \text { solutions - materials for decimetre waves }
\end{aligned}
$$

$\mathrm{Ba}_{6-x} \mathrm{Ln}_{8+2 x / 3} \mathrm{Ti}_{18} \mathrm{O}_{54}$ solid solutions (known as barium lanthanide titanates - BLTss) are, to date, the most promising candidates for the synthesis of new high-permittivity $(\varepsilon \approx 70-100)$ dielectric ceramics with near-zero temperature coefficient of resonant frequency $\left(\tau_{\mathrm{f}}\right)$ [1-3]. BLTss have the structure of tetragonal tungsten bronze with three types of structural sites in the complex A-sublattice: pentagonal sites filled with $\mathrm{Ba}^{2+}$ ions, tetragonal sites shared by $\mathrm{Ba}^{2+}$ and $\mathrm{Ln}^{3+}$ ions, and empty trigonal sites [4-6]. In the BLTss the dielectric properties strongly depend on the size of the A-site ions $\left(r_{\mathrm{A}}\right)[6,7]$. For a fixed $x$, both the permittivity and dielectric loss $(\operatorname{tg} \delta)$ demonstrate an increase with the increasing ionic size of rare-earth element from Sm to La [4-7]. Moreover, any increase in the average size of A-site ions $\left(r_{\mathrm{A}}\right)$ due to the changes in $x$, results in a similar behaviour of $\varepsilon$ and $\operatorname{tg} \delta$. At the same time, the temperature 
coefficient $\tau_{\mathrm{f}}$ slightly increases with $x$, and changes its sign when switching from $\mathrm{Nd}$ to $\mathrm{Sm}[6,7]$. However, regardless of the materials' composition the BLTss generally demonstrate a big scatter in measured properties [4-7]. Therefore, the main problem was how to optimize both the chemical composition of a material and its processing regimes with the view to minimize dielectric loss and obtain controllable values of $\tau_{\mathrm{f}}$.

In this connection we paid particular attention to study the solid-state reaction mechanism for the formation of $\mathrm{Ba}_{6-x} \mathrm{Ln}_{8+2 x / 3} \mathrm{Ti}_{18} \mathrm{O}_{54}$ solid solutions $(\mathrm{Ln}=\mathrm{Nd}, \mathrm{Sm})$. Our data revealed that BLTss start to form with reactions between initial reagents yielding the intermediate products $\mathrm{Ln}_{2} \mathrm{Ti}_{2} \mathrm{O}_{7}, \mathrm{BaTi}_{4} \mathrm{O}_{9}$, and $\mathrm{BaTiO}_{3}$. It has been found that during the interaction of intermediate products, the high- $x$ end members of the $\mathrm{Ba}_{6-x} \mathrm{Ln}_{8+2 x / 3} \mathrm{Ti}_{18} \mathrm{O}_{54}$ solid solutions $\left(\mathrm{Ba}_{3.9} \mathrm{Nd}_{9.4} \mathrm{Ti}_{18} \mathrm{O}_{54}\right.$ and $\mathrm{Ba}_{3.9} \mathrm{Sm}_{9.4} \mathrm{Ti}_{18} \mathrm{O}_{54}$ ) are formed during the first stage. Subsequently, these react with the residual $\mathrm{BaTiO}_{3}$ to produce the intended $\mathrm{Ba}_{6-x} \mathrm{Ln}_{8+2 x / 3} \mathrm{Ti}_{18} \mathrm{O}_{54}$ composition. Since it was difficult to unambiguously distinguish the $\mathrm{Ba}_{3.9} \mathrm{Ln}_{9.4} \mathrm{Ti}_{18} \mathrm{O}_{54}$ phase from the results of X-ray phase analysis, we therefore, identified this phase by means of both EDX and TEM analyses [8]. TEM investigations revealed that even when all of the $\mathrm{BaTiO}_{3}$ reacted, compositional homogeneity was still not necessarily achieved. The ceramics sintered for a short time consisted of both low- $x$ and high$x \mathrm{Ba}_{6-x} \mathrm{Ln}_{8+2 x / 3} \mathrm{Ti}_{18} \mathrm{O}_{54}$ phases, and were characterized by a significant concentration of the crystal-structure defects (Fig. 1). The concentration of crystal-structure defects was suppressed and the compositional homogeneity of $\mathrm{Ba}_{6-x} \mathrm{Ln}_{8+2 x / 3} \mathrm{Ti}_{18} \mathrm{O}_{54}$ was improved after an extended period of sintering $(\geq 3 \mathrm{~h})$. The improved microstructure of BLTss successfully resulted in the corresponding decrease in the dielectric loss measured at microwave frequency.

In order to clear up the origin of the observed changes in $\tau_{\mathrm{f}}$ sign and magnitude with the BLTss family we carefully examined temperature dependences of both $\varepsilon$ and $\operatorname{tg} \delta$ for various BLTss, members [9]. Within the solid solubility range of BLTss, the diffuse maximum of $\varepsilon(T)$ and the corresponding maxima of $\operatorname{tg} \delta(T)$ have been revealed for various rare-earth containing analogues, with the composition corresponding to different $x$ values (Fig. 2). Whereas in lanthanum and neodymium containing materials the anomalies of $\varepsilon(T)$ and $\operatorname{tg} \delta(T)$ were observed at low temperatures (of about -150 to $-100{ }^{\circ} \mathrm{C}$ ), in the case of samarium containing analogues they occur at much higher temperatures (of about $+100^{\circ} \mathrm{C}$ ). For the fixed $x$ the revealed anomalies shift towards high temperatures with decreasing ionic radii of rare-earth element from that of La to that of Sm (Fig. 2). The similar behaviour (shift toward higher temperatures) of anomaly regions has been observed for the fixed rare-earth element (La, $\mathrm{Nd}$, or $\mathrm{Sm}$ ) with the decrease in $x$, when the amount of rare-earth ions is suppressed (Fig. 3). In general, any increase in the average size $\left(r_{\mathrm{AT}}\right)$ of the ions which occupy tetragonal sites (shared by $\mathrm{Ba}^{2+}$ and $\mathrm{Ln}^{3+}$ ) is accompa-

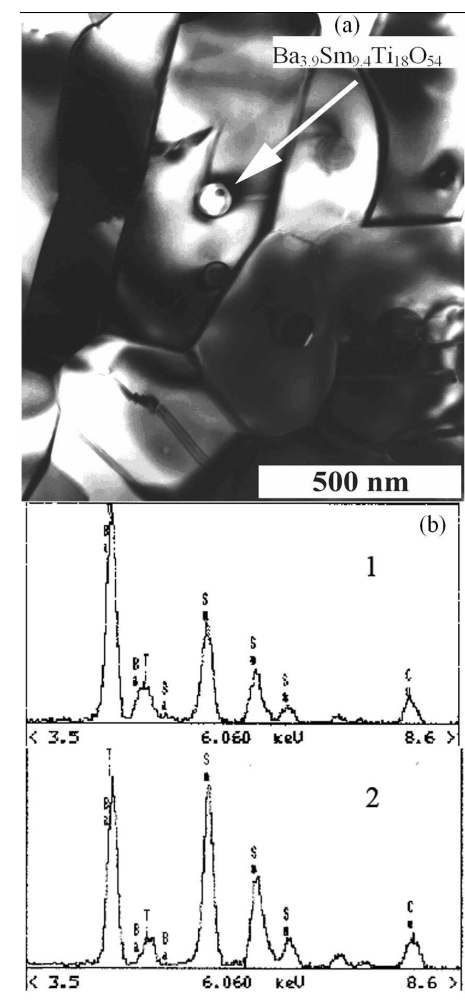
$\begin{array}{lll}\text { Fig. 1. TEM } & \text { microphotographs } & \text { (a) } \\ \mathrm{Ba}_{4.5} \mathrm{Sm}_{9} \mathrm{Ti}_{18} \mathrm{O}_{54} \quad(x=1.5) \text { of } \\ \text { sintered at } 1370{ }^{\circ} \mathrm{C}\end{array}$ for $1 \mathrm{~h}$ and corresponding EDS spectra (b) of the matrix $\mathrm{Ba}_{4.5} \mathrm{Sm}_{9} \mathrm{Ti}_{18} \mathrm{O}_{54}$ (1) and microinclusions of $\mathrm{Ba}_{3.9} \mathrm{Sm}_{9.4} \mathrm{Ti}_{18} \mathrm{O}_{54}(2)$.

nied by a temperature shift of the observed anomalies towards higher temperatures, whereas any decrease in $r_{\mathrm{AT}}$ results in the opposite effect - shift of an anomaly region towards lower temperatures. Here, it should be noted that no structural phase transitions around the regions of anomalies have been found in the entire BLTss family.

Taking into account that in the MW range the permittivity of the low-loss dielectrics, for instance those based on BLTss, is mainly determined by the contribution of elastic-strain "infrared" polarization mechanism, the temperature behaviour of "infrared" permittivity can be considered in terms of a simple model of the harmonic oscillator, for which the restoring force acting on an ion shifted a distance $x_{i}$ under the applied field $(E)$ can be expressed as $f_{\mathrm{R} i}=-c_{i} x_{i}$. In the harmonic approximation, with increasing temperature, the ionic interaction is reduced $\left(x_{i}\right.$ increases due to the increase in the unit-cell volume), which results in a lowering $f_{\mathrm{R} i}$. The anharmonic contribution of the lattice oscillations to the restoring force $f_{\mathrm{R} i}$ in the first approximation could be linearly dependent on the temperature component $\beta$ to give $f_{\mathrm{R} i}=-\left(c_{i}+\beta T\right) x_{i}[9,10]$. According to the above consideration an increase in the temperature initiates two different effects: reducing $f_{\mathrm{R} i}$ (harmonic contribution), and increasing $\beta$ (anharmonic contribution). Whereas 


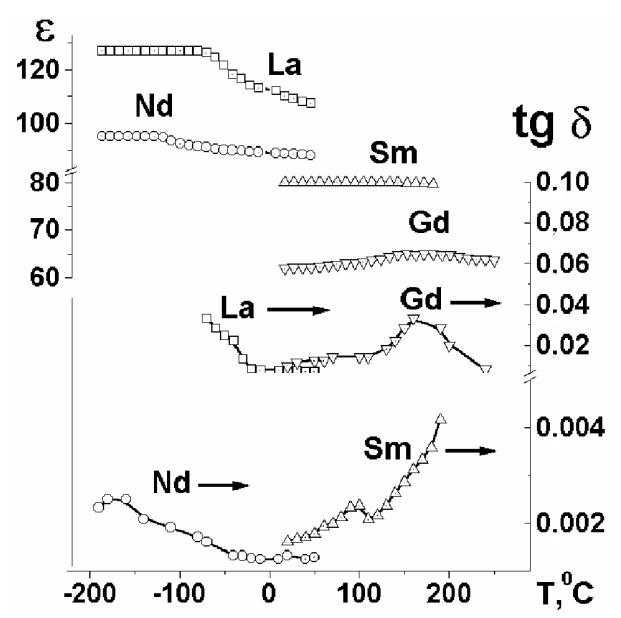

Fig. 2. Temperature dependences of the permittivity $(\varepsilon)$ and dielectric loss tangent $(\operatorname{tg} \delta)$ of the $\mathrm{Ba}_{6-x} \mathrm{Ln}_{8+2 x / 3} \mathrm{Ti}_{18} \mathrm{O}_{54}$ materials $(\mathrm{Ln}=\mathrm{La}, \mathrm{Nd}, \mathrm{Sm}$, Gd) for $x=1.5$, measured at $10^{10} \mathrm{~Hz}$.

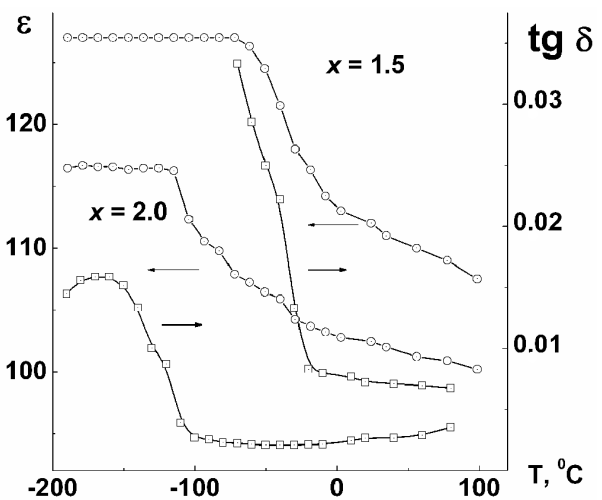

Fig. 3. Temperature dependences of the permittivity $(\varepsilon)$ and dielectric loss tangent $(\operatorname{tg} \delta)$ of the $\mathrm{Ba}_{6-x} \mathrm{La}_{8+2 x / 3} \mathrm{Ti}_{18} \mathrm{O}_{54}$ materials measured at $10^{10} \mathrm{~Hz}$.

the former effect results in the increase in permittivity, the latter one causes the permittivity to decrease with temperature in such a way that higher $\beta$ values correspond to higher negative values of the temperature coefficient of the permittivity $\tau_{\varepsilon}$. Therefore, the $\varepsilon(T)$ behaviour can be interpreted as a superposition of two different, competing contributions. The resulting effect of these contributions in a certain temperature range induces the presence of diffuse anomalies observed on the dependences of $\varepsilon(T)$ in the materials studied. The main conclusion from the above consideration consists in the fact that in the BLTss we can efficiently control the temperature dependence of the permittivity merely by shifting the regions of anomalies along the temperature axis. This can be implemented, for instance by a partial isovalent substitution in the A-sublattice of a BLT [11].

According to our data [11], in partially substituted BLTss corresponding to the sys- tems $\left(\mathrm{Ba}_{1-y} \mathrm{~Pb}_{y}\right)_{6-x} \mathrm{Nd}_{8+2 x / 3} \mathrm{Ti}_{18} \mathrm{O}_{54} \quad$ and $\left(\mathrm{Ba}_{1-y} \mathrm{Ca}_{y}\right)_{6-x} \mathrm{Sm}_{8+2 x / 3} \mathrm{Ti}_{18} \mathrm{O}_{54}$ the shift of the anomalies of $\varepsilon(T)$ and $\operatorname{tg} \delta(T)$ toward higher and lower temperatures, respectively, has been revealed with increasing the content of substituting ion $\left(\mathrm{Pb}^{2+}\right.$ or $\left.\mathrm{Ca}^{2+}\right)$, in accordance with changes in the average size $\left(r_{\mathrm{AT}}\right)$ of the ions at tetragonal sites (Fig. 4). In this case, a slight shift of the $\varepsilon(T)$ anomalies along the $T$-axis is accompanied by the degradation of $\varepsilon(T)$ maxima (Fig. 4), that consequently results in the reduction of the temperature coefficient $\tau_{\varepsilon}$. Therefore, by varying both - the ratio between the A-site ions (change in $x$ ) and the concentration of substituting ion in the BLTss, we can obtain the materials with high permittivity and quality-factor, and near-zero controllable temperature coefficient $\tau_{\mathrm{f}}$ (Table I).

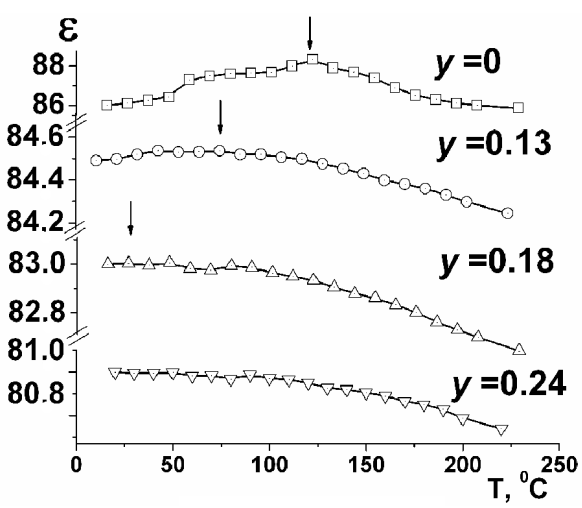

Fig. 4. Temperature dependences of the dielectric permittivity $\varepsilon(T)$ of the $\left(\mathrm{Ba}_{1-y} \mathrm{Ca}_{y}\right)_{5} \mathrm{Sm}_{8.6(6)} \mathrm{Ti}_{18} \mathrm{O}_{54}$ $(x=1.0)$ materials measured at $10^{10} \mathrm{~Hz}$.

TABLE I

Microwave dielectric parameters of the developed materials based on $\mathrm{Ba}_{6-x} \mathrm{Ln}_{8+2 x / 3} \mathrm{Ti}_{18} \mathrm{O}_{54}$.

\begin{tabular}{c|c|c|c}
\hline \hline \multirow{2}{*}{ Composition } & \multicolumn{3}{|c}{ Our data } \\
\cline { 2 - 4 } & $\varepsilon$ & $\begin{array}{c}\text { Qxf }[\mathrm{GHz}] \\
\text { at } 10 \mathrm{GHz}\end{array}$ & $\begin{array}{c}\tau_{\mathrm{f}} \\
{[\mathrm{ppm} / \mathrm{K}]}\end{array}$ \\
\hline $\begin{array}{c}\mathrm{Ba}_{6-x}\left(\mathrm{Nd}_{y} \mathrm{Sm}_{1-y}\right)_{8+2 x / 3} \mathrm{Ti}_{18} \mathrm{O}_{54} \\
(x=1.5-2.0 ; y=0.3-0.4)\end{array}$ & $75-80$ & $8000 \div 10000$ & $2 \div 5$ \\
\hline $\begin{array}{c}\left(\mathrm{Ba}_{1-y} \mathrm{Ca}_{y}\right)_{6-x} \mathrm{Sm}_{8+2 x / 3} \mathrm{Ti}_{18} \mathrm{O}_{54} \\
(x=0-1.0 ; y=0.1-0.2)\end{array}$ & $80-82$ & $10000 \div 15000$ & $-2 \div 2$ \\
\hline $\begin{array}{c}\left(\mathrm{Ba}_{1-y} \mathrm{~Pb}_{y}\right)_{6-x} \mathrm{Nd}_{8+2 x / 3} \mathrm{Ti}_{18} \mathrm{O}_{54} \\
(x=0-0.75 ; y=0.25-0.5)\end{array}$ & $90-95$ & $5000 \div 6000$ & $2 \div 10$
\end{tabular}

$$
\begin{aligned}
& \text { 2.2. } \mathrm{Ba}\left(\mathrm{M}_{1 / 3}^{2+} \mathrm{Nb}_{2 / 3}\right) \mathrm{O}_{3}(\mathrm{M}=\mathrm{Co}, \mathrm{Zn}, \mathrm{Mg}) \\
& \text { ordered perovskites - materials for centimetre } \\
& \text { and millimetre waves }
\end{aligned}
$$

During the last decades, the complex perovskites $\mathrm{Ba}\left(\mathrm{A}_{1 / 3}^{2+} \mathrm{B}_{2 / 3}^{5+}\right) \mathrm{O}_{3} \quad\left(\mathrm{~A}^{2+}=\mathrm{Mg}, \mathrm{Co}, \mathrm{Zn} ; \mathrm{B}^{5+}=\mathrm{Ta}, \mathrm{Nb}\right)$ have been generally considered as the most promising candidates to obtain the product $Q \times f \geq 100000 \mathrm{GHz}$ 
$[2,12,13]$. The main characteristic feature of the high$-Q$ perovskites $\mathrm{Ba}\left(\mathrm{A}_{1 / 3}^{2+} \mathrm{B}_{2 / 3}^{5+}\right) \mathrm{O}_{3}$ is the presence of $1: 2$ ordered superstructure in their B-sublattice, which comprises single layers of $\mathrm{A}^{2+}$ cations alternating with double layers of $\mathrm{B}^{5+}$ cations perpendicular to the $\langle 111\rangle$ direction of the pseudocubic cell [14]. In this case the tripled unit cell of the cubic perovskite can be represented as $\mathrm{Ba}_{3} \mathrm{~A}^{2+} \mathrm{B}_{2}^{5+} \mathrm{O}_{9}$. It is well established that B-site cation ordering in complex perovskites has a significant influence on the dielectric losses ( $Q$-factor) at microwave frequences $[15,16]$. Usually, long-time sintering and annealing are required to ensure a high degree of the cation ordering in the perovskites $\mathrm{Ba}\left(\mathrm{A}_{1 / 3}^{2+} \mathrm{B}_{2 / 3}^{5+}\right) \mathrm{O}_{3}[12,15,16]$. However, the ordering processes can be significantly promoted by the changes in chemical composition of a material, that is observed, for instance in $\mathrm{BaZrO}_{3}$ doped $\mathrm{Ba}\left(\mathrm{Zn}_{1 / 3} \mathrm{Ta}_{2 / 3}\right) \mathrm{O}_{3}$ (BZT) [15]. Davies et al. [15] have found that the formation of 1:2 ordered structure in these materials starts in small-size domains distributed in the disordered matrix [15]. They have shown the important role of $\mathrm{Zr}^{4+}$ in the stabilization of domain walls that facilitates ordering processes in a material, and hence improves its $Q$-factor magnitude. However, beyond the degree of the B-site cation ordering in $\mathrm{Ba}\left(\mathrm{A}_{1 / 3}^{2+} \mathrm{B}_{2 / 3}^{5+}\right) \mathrm{O}_{3}$ perovskites other factors like the presence of secondary phases, microstructural defects or the grain size may contribute to the variation of the $Q$-factor in the ceramic materials. In our opinion, the effect of these factors can be obviously promoted in the non-stoichiometric composition. Therefore, some of the composition-derived changes in the microstructure, ordering degree, and the $Q$-factor variation of selected high- $Q$ niobate based perovskites are below summarized and discussed.

\subsubsection{The system $\mathrm{Ba}_{3} \mathrm{Co}_{1+x} \mathrm{Nb}_{2} \mathrm{O}_{9+x}$}

In this system single-phase materials are formed at $-0.02 \leq x \leq 0.02$. It should be noted that the formula $\mathrm{Ba}_{3} \mathrm{Co}_{1+x} \mathrm{Nb}_{2} \mathrm{O}_{9+x}$ represents the nominal composition only, and hence, in the case of positive $x$ (overstoichiometric excess of $\mathrm{Co}$ ) the structure merely corresponds to the deficiency in both $\mathrm{Ba}$ and $\mathrm{Nb}$. At lower $x(x<-0.02)$ a secondary $\mathrm{Ba}_{8} \mathrm{CoNb}_{6} \mathrm{O}_{24}$ phase with the layered perovskite structure is formed (Fig. 5). The increase in the amount of secondary phase with the Co-deficiency (decrease in $x$ ) is accompanied by a substantial decrease in the grain size of the ceramics (Fig. 6). The $Q$-factor of the Co-deficient $\mathrm{BCN}$ increases with decreasing $x$, and attains the maximum magnitude at around $x=-0.07$, when the material contains small amount of $\mathrm{Ba}_{8} \mathrm{CoNb}_{6} \mathrm{O}_{24}$ (Fig. 7). Most likely, the formation of secondary $\mathrm{Ba}_{8} \mathrm{CoNb}_{6} \mathrm{O}_{24}$ phase, which starts as the intergrowth structure of the BCN matrix (Fig. 5), inhibits the grain growth of a BCN material, and hence contributes to the stabilization of the microstructure of a multiphase material, which consequently demonstrates the highest $Q$ values.

Therefore, from the experimental results we can state that the improved ordering in the Co-deficient $\mathrm{BCN}$ is not

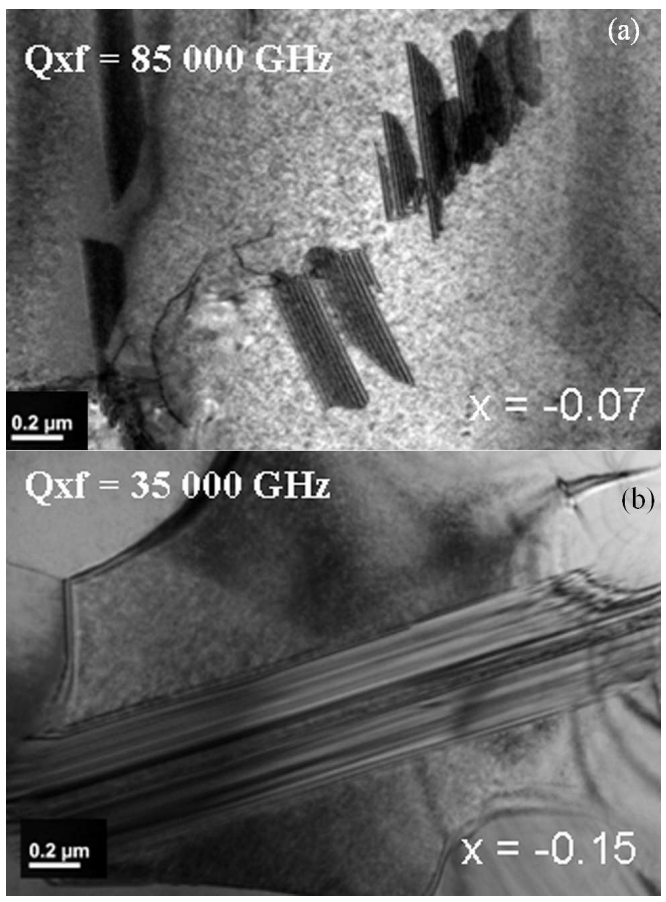

Fig. 5. TEM images of $\mathrm{Ba}_{3} \mathrm{Co}_{1+x} \mathrm{Nb}_{2} \mathrm{O}_{9+x}$ grains for (a) $x=-0.07$ and (b) $x=-0.15$ displaying the intergrowths of layered $\mathrm{Ba}_{8} \mathrm{CoNb}_{6} \mathrm{O}_{24}$ perovskite.

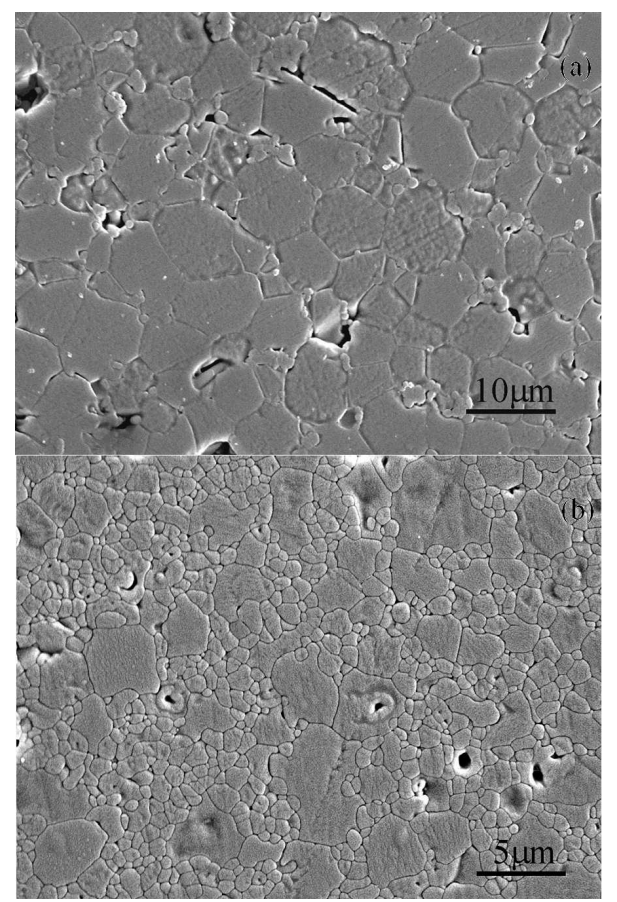

Fig. 6. SEM microphotographs of the etched surface of $\mathrm{Ba}_{3} \mathrm{Co}_{1+x} \mathrm{Nb}_{2} \mathrm{O}_{9}$ samples sintered at $1470{ }^{\circ} \mathrm{C}(8 \mathrm{~h})$ : (a) $x=0$, (b) $x=-0.07$. 


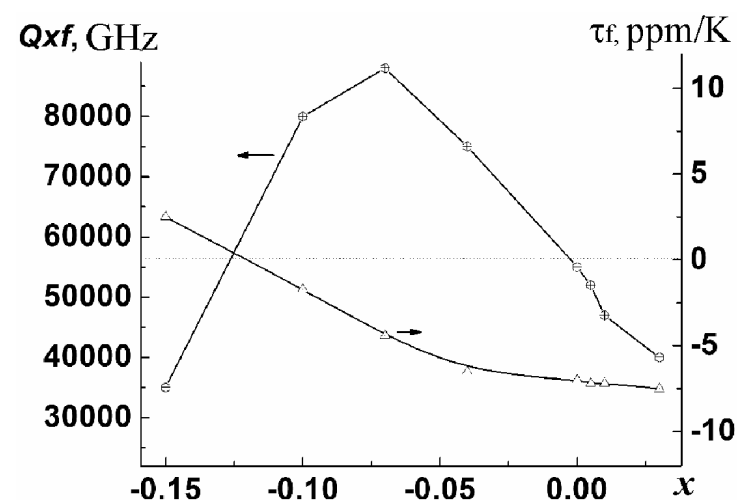

Fig. 7. $Q x f$ product and the temperature coefficient of resonant frequency $\left(\tau_{\mathrm{f}}\right)$ of the $\mathrm{Ba}_{3} \mathrm{Co}_{1+x} \mathrm{Nb}_{2} \mathrm{O}_{9}$ materials as a function of Co content, measured at $10 \mathrm{GHz}$.

the main factor responsible for the rise in the $Q$-factor. Actually, the highest values of $Q$ can be attributed to the changes in the microstructure of a material rather than to the direct effect of the secondary $\mathrm{Ba}_{8} \mathrm{CoNb}_{6} \mathrm{O}_{24}$. Although this phase exhibits high enough microwave dielectric parameters $(Q$ is comparable with that of $\mathrm{BCN})$, its increasing amount $x<-0.07$ monotonically deteriorates the $Q$-factor of the multiphase material (Fig. 7). In this case, the reason for the observed degradation of $Q$ can be the increasing number of microstructural defects arising from the growth of $\mathrm{Ba}_{8} \mathrm{CoNb}_{6} \mathrm{O}_{24}$ inclusions along the $\mathrm{BCN}$ grains (Fig. 5b). However, this effect is negligible in the case of small-size inclusions of $\mathrm{Ba}_{8} \mathrm{CoNb}_{6} \mathrm{O}_{24}$ (Fig. 5a), which are observed when the deviation from compositional stoichiometry is small $(-0.07 \leq x \leq 0.02)$.

In addition to the influence on the $Q$-factor of a non-stoichiometric $\mathrm{BCN}$, we have found much more positive effect of the $\mathrm{Ba}_{8} \mathrm{CoNb}_{6} \mathrm{O}_{24}$ on the temperature coefficient of resonant frequency $\left(\tau_{\mathrm{f}}\right)$ of a multiphase material: $\tau_{\mathrm{f}}$ changes its sign with the increasing concentration of $\mathrm{Ba}_{8} \mathrm{CoNb}_{6} \mathrm{O}_{24}$ within the range $-0.15 \leq x \leq-0.1$ (Fig. 7). This fact can be attributed to the opposite signs of $\tau_{\mathrm{f}}$ in the individual impurity phase $\mathrm{Ba}_{8} \mathrm{CoNb}_{6} \mathrm{O}_{24}$ $\left(\tau_{\mathrm{f}}=+12 \mathrm{ppm} / \mathrm{K}\right)$ and matrix BCN $\left(\tau_{\mathrm{f}}=-7 \mathrm{ppm} / \mathrm{K}\right)$. As a consequence, at a certain ratio of constituting phases in the Co-deficient $\mathrm{BCN}$, the volume temperature compensation effect is realised. This allows to obtain the temperature stable dielectrics with high quality factor of around $80000 \mathrm{GHz}$, simply by a proper adjustment of Co concentration.

\subsubsection{The system $\mathrm{Ba}_{3+3 x} \mathrm{MgNb}_{2} \mathrm{O}_{9+3 x}$}

In this system the materials can be sintered only when $x \leq 0$. It should be noted that the formula $\mathrm{Ba}_{3} \mathrm{Mg}_{1+x} \mathrm{Nb}_{2} \mathrm{O}_{9+x}$ represents the nominal composition only, and hence, in the case of positive $x$ (overstoichiometric excess of $\mathrm{Mg}$ ) the structure merely corresponds to the deficiency in both $\mathrm{Ba}$ and $\mathrm{Nb}$. However, when $x>0$, the sintering temperature sharply increases over $1600^{\circ} \mathrm{C}$, and the ceramics is never dense enough. When $-0.03 \leq x \leq 0$, the sintered materials contain only ma- trix perovskite phase BMN (Fig. 8a). At lower $x$, new secondary phase can be detected by the XRD (Fig. 8a). The peaks of this phase coincide with those of ferroelectric $\mathrm{Ba}_{6} \mathrm{CoNb}_{9} \mathrm{O}_{30}$ with the tetragonal tungsten bronze (TTB) structure. However, this secondary compound is hardly recognizable by SEM since it is distributed at grain boundaries as a liquid phase (because of its low melting temperature), and is pulled out when polished. In contrast to BCN perovskites all of the studied BMN materials demonstrate good ordering (Fig. 8a).

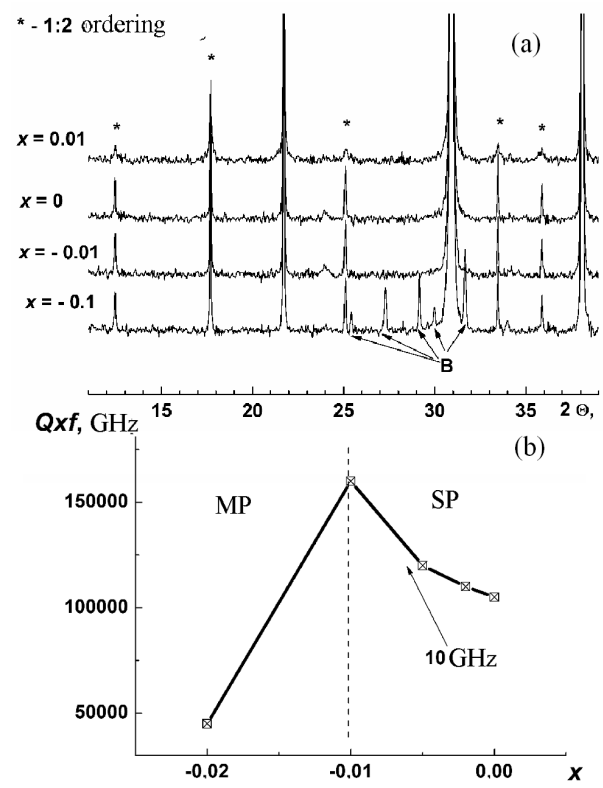

Fig. 8. XRD patterns (a), and the $Q x f$ product (b) of $\mathrm{Ba}_{3+3 x} \mathrm{MgNb}_{2} \mathrm{O}_{9+3 x}$ ceramics with different $\mathrm{Ba}$ content: $\mathrm{B}-\mathrm{Mg}$-containing analogue of ferroelectric $\mathrm{Ba}_{6} \mathrm{CoNb}_{9} \mathrm{O}_{30} ; \mathrm{MP}$ - multiphase region, $\mathrm{SP}$ - single-phase region.

Similarly to the data obtained for the Co-deficient $\mathrm{BCN}$, the microwave quality factor of BMN increases with increasing Ba-deficiency, and passes through maximum at $x=-0.01$ (Fig. $8 \mathrm{~b}$ ). However, from the XRD no clear relationship can be found between ordering degree and the product $Q x f$ (Fig. 8). Probably, in the well ordered BMN the variation in $Q$ is stipulated by the material's microstructure, similarly like it was found in the Co-containing niobate perovskites. In fact, our results show that the less porous structure corresponds to the highest $Q x f$ product of $150000 \mathrm{GHz}$. At the same time $Q x f$ as high as $120000 \mathrm{GHz}$ has been obtained in more porous ceramics with stoichiometric composition.

Deriving from the experimental results, it is possible to define several competing factors which are foremost responsible for the variation of the $Q$-factor in the $\mathrm{Ba}_{3+x} \mathrm{MgNb}_{2} \mathrm{O}_{9}$ materials, namely, (a) high degree of 1:2 cation ordering, (b) the improved microstructure of the Ba-deficient BMN material, and (c) the possible presence of undesirable secondary phase ( $\mathrm{Mg}$-containing analogue of ferroelectric $\left.\mathrm{Ba}_{6} \mathrm{CoNb}_{9} \mathrm{O}_{30}\right)$. The effect of the latter 
factor can in many cases prevail over the others.

As a consequence of the compositional changes induced in the ordered niobate perovskites $\mathrm{Ba}\left(\mathrm{A}_{1 / 3} \mathrm{Nb}_{2 / 3}\right) \mathrm{O}_{3}$ $(\mathrm{A}=\mathrm{Co}, \mathrm{Mg})$, we have developed new dielectric materials with extremely high quality-factors comparable with those attained previously in the Ta-containing analogues (Table II).

TABLE II

Microwave dielectric parameters of the developed materials based on $\mathrm{Ba}\left(\mathrm{A}_{1 / 3}^{2+} \mathrm{Nb}_{2 / 3}\right) \mathrm{O}_{3}\left(\mathrm{~A}^{2+}=\mathrm{Co}, \mathrm{Mg}\right)$.

\begin{tabular}{c|c|c|c}
\hline \hline \multirow{2}{*}{ Composition } & \multicolumn{3}{|c}{ Our Data } \\
\cline { 2 - 4 } & $\varepsilon$ & $\begin{array}{c}\text { Qxf [GHz] } \\
\text { at } 10 \mathrm{GHz}\end{array}$ & $\begin{array}{c}\tau_{\mathrm{f}} \\
{[\mathrm{ppm} / \mathrm{K}]}\end{array}$ \\
\hline $\mathrm{Ba}_{3+3 x} \mathrm{MgNb}_{2} \mathrm{O}_{9+3 x}$ & 32 & $\begin{array}{c}150000 \\
(x=-0.005)\end{array}$ & $10 \div 25$ \\
\hline $\mathrm{Ba}_{3} \mathrm{Co}_{1+x} \mathrm{Nb}_{2} \mathrm{O}_{9+x}$ & 34 & $\begin{array}{c}85000-100000 \\
(x=-0.07)\end{array}$ & $-5 \div 5$ \\
\hline $\mathrm{Ba}_{3+3 x} \mathrm{ZnNb}_{2} \mathrm{O}_{9+3 x}$ & 40 & $\begin{array}{c}90000-100000 \\
(x=-0.02)\end{array}$ & $10 \div 25$
\end{tabular}

\subsection{Implementation of the developed materials}

The above discussed consideration allowed us to optimize the chemical composition and processing regimes of new microwave materials for the decimetre and centimetre wavelength bands (Tables I and II). The materials with the optimal parameters have been used for the production of dielectric resonators (DR) operating on different oscillation modes. The choice of the DR's oscillation mode derives from the specific requirements of operating frequency. For instance, the materials based on $\mathrm{Ba}_{6-x} \mathrm{Ln}_{8+2 x / 3} \mathrm{Ti}_{18} \mathrm{O}_{54}$ were used for the TEM (coaxial) DRs, which allows the maximum size reduction. These materials have been implemented in various designs of radio and TV filters (Fig. 9a). In contrast, the $\mathrm{Ba}\left(\mathrm{A}_{1 / 3} \mathrm{Nb}_{2 / 3}\right) \mathrm{O}_{3}$ materials with the extremely high quality factors were used for the production of the DRs operating at $\mathrm{TE}_{01 \delta}$ oscillation mode, which ensures maximum unloaded $Q$-factor of a resonator. These DRs have been implemented in new designs of ultra narrow-band filters and low-phase-noise microwave oscillators operating at the frequencies of $6-12 \mathrm{GHz}$ (Fig. 9b).

\section{Conclusions}

In this work two classes of microwave dielectrics have been discussed including those based on the barium lanthanide solid solutions $\mathrm{Ba}_{6-x} \mathrm{Ln}_{8+2 x / 3} \mathrm{Ti}_{18} \mathrm{O}_{54}$ and the complex ordered $\mathrm{Ba}\left(\mathrm{A}_{1 / 3} \mathrm{Nb}_{2 / 3}\right) \mathrm{O}_{3}$ perovskites. In the first class of materials an improvement of materials' microstructure due to the proper choice of processing regimes allowed us to significantly reduce the dielectric loss. Moreover, in these materials we found the presence of the anomalies on the $\varepsilon(T)$ and $\operatorname{tg} \delta(T)$ dependences, which have been attributed to the competing

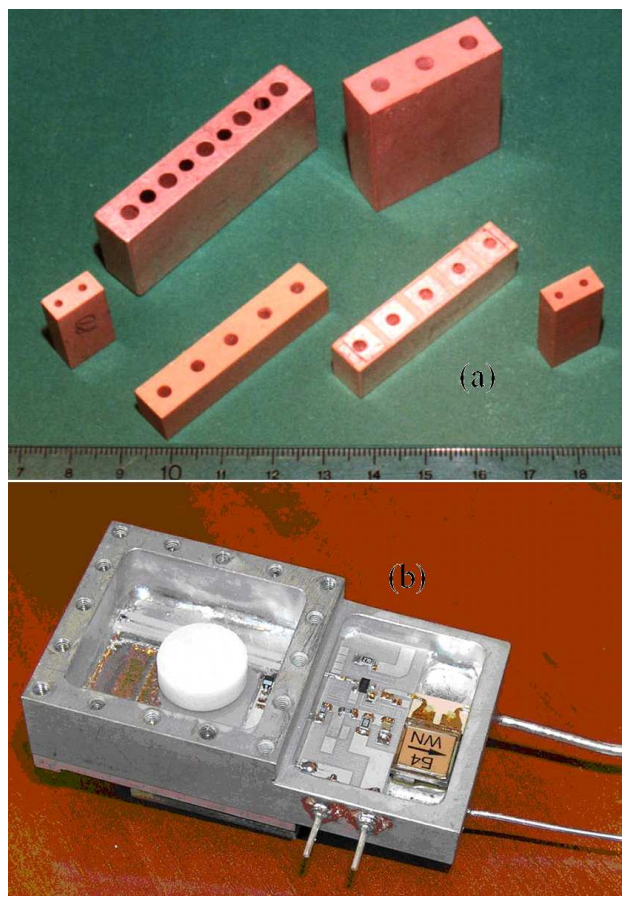

Fig. 9. Monolithic ceramic blocks for the utilization in radiofilters operating in the decimetre wavelength band (a), and low-noise microwave oscillator for the frequency of around $9 \mathrm{GHz}(\mathrm{b})$..

effect of both harmonic and anharmonic contributions to the lattice oscillations. This fact allowed us to develop the series of new dielectric materials with improved properties, which were controllable merely by partial isoand aliovalent substitution in the cation sublattices of $\mathrm{Ba}_{6-x} \mathrm{Ln}_{8+2 x / 3} \mathrm{Ti}_{18} \mathrm{O}_{54}$. In the materials based on the complex ordered $\mathrm{Ba}\left(\mathrm{A}_{1 / 3} \mathrm{Nb}_{2 / 3}\right) \mathrm{O}_{3}$ perovskites we have shown that a slight deviation from compositional stoichiometry may result in a prominent improvement of the microwave quality factor. As a consequence of the presented research, new efficient microwave dielectric resonators operating on different oscillation modes have been produced and implemented in the equipment for modern communication systems.

\section{References}

[1] W. Wersing, Curr. Opin. Solid State Mater. Sci. 1, 715 (1996).

[2] M.T. Sebastian, Dielectric Materials for Wireless Communication, Elsevier, Oxford, U.K. 2008, p. 668.

[3] A.G. Belous, J. Europ. Ceram. Soc. 21, 2717 (2001).

[4] R.G. Matveeva, M.B. Varfolomeev, L.S. Ilyuhchenko, Russ. J. Inorg. Chem. 29, 17 (1984).

[5] D. Kolar, Z. Stadler, S. Gaberšček, D. Suvorov, Ber. Dt. Keram. Ges. B 55, 346 (1978).

[6] H. Ohsato, M. Mizuta, T. Ikoma, Z. Onogi, S. Nishigaki, T. Okuda, J. Ceram. Soc. Japan 106, 178 (1998). 
[7] T. Negas, P.K. Davies, Materials and Processes for Wireless Communications, Ceram. Trans. 53, 179 (1995).

[8] A. Belous, O. Ovchar, M. Valant, D. Suvorov, J. Mater. Res. 16, 2350 (2001).

[9] A. Belous, O. Ovchar, M. Valant, D. Suvorov, J. Appl. Phys. 92, 3917 (2002).

[10] Y.M. Poplavko, Physics of Dielectrics, Vyshcha Shkola, Kiev 1980, p. 243 (in Russian).

[11] A. Belous, O. Ovchar, M. Valant, D. Suvorov, D. Kolar, J. Europ. Ceram. Soc. 21, 2723 (2001).
[12] S. Kawashima, M. Nishida, I. Ueda, H. Ouchi, S. Hayakawa, Proc. Ferroelect. Mater. Appl. 1, 293 (1977).

[13] H. Matsumoto, H. Tamura, K. Wakino, Jpn. J. Appl. Phys. 30, 2347 (1991).

[14] F. Galasso, J. Pyle, Inorg. Chem. 2, 482 (1963).

[15] P.K. Davies, J. Tong, T. Negas, J. Am. Ceram. Soc. 80, 1724 (1997).

[16] T. Kolodiazhnyi, A. Petric, A. Belous, O. V'yunov, O. Yanchevskij, J. Mater. Res. 17, 3182 (2002). 